Article

\title{
The Use of the Value of Heat Cycle to Assess the Energy Stability of Permafrost Soils at the Change of Conditions on the Surface
}

\author{
Anatoly Kulikov ${ }^{1}$, Nimazhap Badmaev ${ }^{1,2}$, Darima Sympilova ${ }^{1, *}$ and Ayur Gyninova ${ }^{1,3}$ \\ 1 Institute of General and Experimental Biology, Siberian Branch, Russian Academy of Sciences, \\ Sakhyanovoi str.6, 670000 Ulan-Ude, Russia; kul-an52@mail.ru (A.K.); nima_b@mail.ru (N.B.); \\ ayur.gyninova@mail.ru (A.G.) \\ 2 Buryat State University, Smolina str. 24a, 670000 Ulan-Ude, Russia \\ 3 Buryat Agricultural Academy. V.R. Filippova, Pushkin str. 8, 670000 Ulan-Ude, Russia \\ * Correspondence: darimasp@mail.ru; Tel.: +30-124-338-55
}

Received: 29 October 2018; Accepted: 22 February 2019; Published: 1 March 2019

check for updates

\begin{abstract}
The basis for assessing the stability of geosystems to changes in external heat cycle conditions is the calculation method. It is shown that permafrost soils are characterized by increased values of annual heat cycle $Q_{Y} \geq 300 \mathrm{MJ} / \mathrm{m}^{2}$, i.e., half-sum of heat arrival and flow rate per year. This is due to the high heat consumption for melting soils $\left(Q_{P h}=0.7-0.8 Q_{Y}\right)$ and warming them in the negative temperature range $\left(Q_{F}\right)$. The heat cycle in frozen soil $\left(Q_{F}\right)$ always has more heat cycle than in the thawed soil $\left(\mathrm{Q}_{\mathrm{H}}\right)$. The condition $\mathrm{Q}_{\mathrm{F}}>\mathrm{Q}_{\mathrm{H}}$ means the dominance of processes occurring at negative temperature, and the difference $\mathrm{Q}_{\mathrm{F}}-\mathrm{Q}_{\mathrm{H}}$ is a quantitative assessment of the energy stability of soils to changes in heat exchange conditions on the surface.
\end{abstract}

Keywords: permafrost soils; heat cycle; thermal and energy stabilities; Cryosols

\section{Introduction}

From the analysis of numerous definitions [1], the energy stability of permafrost soils should be understood as their ability to withstand global temperature rise, structural organization, and system connections within the limits sufficient to perform basic functions. M.D. Grodzinsky distinguishes three forms of the manifestation of stability: inertness (i.e., the property of geosystems not to leave an initial state); recoverability (i.e., the property to return to an initial state); and plasticity (i.e., the property to pass from one invariant state to another) [2]. Practically speaking, the same properties studied by V. Skopec, etc., are called persistence, resistance, and resilience [3].

\section{The Following Aspects are Relevant}

1. Permafrost is characterized by diverse geo-ecological features. Summarizing modern ideas, L.S. Garagulya and G.I. Gordeeva [4] developed a scheme of zoning the permafrost zone. Permafrost covers up to $25 \%$ of the land area. This is a testament to the global importance of permafrost soils. In one quarter of the territory of the European part of Russia and in two thirds of its Asian part, the influence of permafrost is estimated as strong or moderate. This means that in the Northern hemisphere, the territory of Russia permafrost plays a global role.

2. Climate warming causes degradation of permafrost and development of adverse processes. The increase of the human loads also leads to degradation of permafrost.

3. With increased thawing, permafrost is associated with such a phenomenon as the emission of carbon dioxide. The process of soil and landscape mercurization may also be activated, as the frozen state contains huge reserves of mercury [5]. 
4. Due to the complexity of natural systems, qualitative approaches are most often used to assess their resistance to external influences. It is of interest to link the environmental sustainability of geosystems with the power of the seasonally thawing layer. The thermophysical basis of this is that the thawing depth integrally reflects the mode of moisture and heat exchange [6]. Deeper seasonal thawing means a more stable state of permafrost. It is important that this increases the capacity to dispose of pollutants [7].

The general goal is to estimate the thermal and energy stability of permafrost soils by quantitative methods when surface conditions change.

The objectives of this paper are as follows: (1) develop methods for calculating heat cycle in soils; (2) obtain the quantitative parameters of heat cycle; (3) determine the thermal stability of soils; (4) group soils into categories of stability.

\section{Materials and Methods}

The quantitative principle is based on the calculation of the coefficient of relative thermal stability. It is the ratio of the amount of heat required to raise the temperature of frozen rocks from $0{ }^{\circ} \mathrm{C}$ to the annual heat cycle [8]. Another method is based on the assessment of temperature and "cold reserve" in underlying permafrost [9]. The lower the temperature and "cold reserve" in rocks, the more stable soil is under external influences.

The assessment method of the thermal energy stability of soils was developed by us as a result of the generalization of long-term research in Central and Northern Asia. It is important to emphasize that the method uses mass soil-hydrothermal information, including information obtained by a network of weather stations. The calculated data are supplemented with the instrumental values of heat flows obtained by different authors [10-12].

As is known, the annual heat cycle ( $\left.Q_{Y}\right)$ is a half-sum of the arrival and consumption of heat for the year [13]. It is composed of three elementary heat cycles: $Q_{F}-$ heat cycle to increase the temperature of the frozen soil from the winter minimum to $0{ }^{\circ} \mathrm{C} ; \mathrm{Q}_{\mathrm{Ph}}$-heat cycle to thaw the soil, i.e., the phase transitions of water; $\mathrm{Q}_{\mathrm{H}}$-heat cycle to increase the melt temperature of the soil from $0{ }^{\circ} \mathrm{C}$ to a maximum in the summer [7].

The following formulas are used:

$$
\begin{gathered}
\mathrm{Q}_{\mathrm{F}}=C_{S}+C_{W} \frac{W_{N F}}{100}+C_{I} \frac{W_{I}}{100} * \gamma_{S} * \Delta t, \\
\mathrm{Q}_{\mathrm{H}}=C_{S}+C_{W} \frac{W}{100} * \gamma_{S} * \Delta t \\
\mathrm{Q}_{\mathrm{Ph}}=335 * \gamma_{S} * W_{S} * h,
\end{gathered}
$$

where $C_{S}, C_{W}$, and $C_{1}$ are the specific heat capacities of soils, water, and ice, respectively (tabulated, e.g., [9]); $W_{S}, W N F$, and $W_{I}$ are the soil moisture content of non-freezing moisture and ice content (in \% by weight); $\gamma_{\mathrm{s}}$ is the density of the skeleton of the soil $\left(\mathrm{kg} / \mathrm{m}^{3}\right) ; \Delta \mathrm{t}$ is the temperature difference between the frozen soil from the winter minimum up to $0{ }^{\circ} \mathrm{C}$ to melt the soil from $0{ }^{\circ} \mathrm{C}$ to a summer maximum; 335 is the specific heat of fusion of ice $(\mathrm{kJ} / \mathrm{kg})$; $\mathrm{h}$ is the depth for thawing soil $(\mathrm{m})$.

\section{Results and Discussion}

To get a more complete picture of the approach, it would be appropriate to briefly consider the features of heat cycles in geosystems with unviolated heat exchange conditions. Parameters in Table 1 were obtained from our experimental data as a result of hydrothermal calculations. The studied soils at the base that remained frozen all year round had a negative average temperature of $-2.0-2.5^{\circ} \mathrm{C}$, and the soils at the base that remained thawed all year round had a positive average temperature of $1.3-1.5^{\circ} \mathrm{C}$. 
Table 1. Thermal power parameters of soils, $\mathrm{MJ} / \mathrm{m}^{2}$.

\begin{tabular}{ccccc}
\hline \multirow{2}{*}{$\mathbf{Q}_{\mathbf{Y}}$} & \multicolumn{5}{c}{ Components of $\mathbf{Q}_{\mathbf{Y}}$} \\
\cline { 2 - 5 } & $\mathbf{Q}_{\mathbf{F}}$ & $\mathbf{Q}_{\mathbf{P h}}$ & $\mathbf{Q}_{\mathbf{H}}$ & $\mathbf{Q}_{\mathbf{F}}-\mathbf{Q}_{\mathbf{H}}$ \\
\hline \multicolumn{5}{c}{ Geosystems of perennial permafrost } \\
\hline 166.7 & 43.4 & 88.3 & 35.0 & 8.4 \\
\hline \multicolumn{5}{c}{ Geosystems of seasonal permafrost } \\
\hline 152.6 & 27.3 & 68.5 & 56.8 & -29.5 \\
\hline
\end{tabular}

In permafrost geosystems, the annual heat cycle is generally higher than in seasonal permafrost, which is caused by large heat consumption for soil thawing. The heat cycle of $\mathrm{Q}_{\mathrm{Ph}}$ is usually more than $50 \% \mathrm{Q}_{\mathrm{Y}}$. The "cold reserve" quantified by the sum of $\mathrm{Q}_{\mathrm{F}}+\mathrm{Q}_{\mathrm{Ph}}$ reaches $80-90 \%$, and when seasonally frozen, does not reach more than $60 \%$ of the value of $Q_{Y}$. Elementary heat $Q_{H}$ is associated with the bioproductivity of geosystems in permafrost areas, and its value does not exceed $20 \%$ QY.

The most optimal method is the direct determination of the annual heat cycle by means of heat meters. However, such studies are few, as indicated by M.K. Gavrilova [11]. The least squares method is used to obtain the regression equation for the calculation of annual heat cycle:

$$
\mathrm{Q}_{\mathrm{Y}}=1.18 \mathrm{Q}_{\mathrm{Ph}}+38.7(\mathrm{r}=0.65 ; \mathrm{P}>0.95),
$$

The choice of $\mathrm{Q}_{\mathrm{Ph}}$ as an independent variable is explained both by the fact that it is easily determined (see the formula above) and by the fact that the humidity, density, and power of the seasonal soil layer are widely represented in the literature. The obtained model has a sufficient level of reliability, as indicated by the level of reliability $(\mathrm{P})$ of the pair correlation $(\mathrm{r})$. By the coefficient determination $\mathrm{r}^{2}=0.42$, it can be judged that this model adequately reflects $42 \%$ of the variance of the dependent variable. Verification shows that the validity of the forecast calculation is $86 \%$ with an error of $14 \%$.

For permafrost regions, the dominance of negative temperatures over positive ones in the annual cycle is characteristic $[13,14]$. This is explained by the fact that during the summer thawing of the active layer, the forming phase boundary shields the underlying permafrost layers from the thermal impulses of the atmosphere, and only in the cold season (after the closure of the seasonal thawing layer with permafrost and the formation of a continuous cryolithozone) is there interaction with the entire layer of annual heat.

In the framework of the approach, this thermophysical phenomenon received a strict mathematical expression that can be used as the basis of thermal soil melioration, and in the context of this topic, served as the basis for the proposed assessment. Thus, in stable permafrost geosystems, the condition $\mathrm{Q}_{\mathrm{F}}>\mathrm{Q}_{\mathrm{H}}$ is always observed, which also indicates that the depth of potential freezing is greater than the depth of actual thawing, i.e., the energy supply of potential freezing can be determined by the difference $\mathrm{Q}_{\mathrm{F}}-\mathrm{Q}_{\mathrm{H}}$. This means that the difference is determined by how much heat energy expenditure is required in order to equalize these depths or to increase the average annual soil temperature to $0{ }^{\circ} \mathrm{C}$ and cause degradation of permafrost. It follows that this thermal energy difference is an important indicator of the stability of the geocryological situation.

The calculations show that the extreme values of the relative $\mathrm{Q}_{\mathrm{F}} / \mathrm{Q}_{\mathrm{H}}$ index proposed for assessing the stability of permafrost geosystems vary widely (Table 2). 
Table 2. Statistical parameters of the $\mathrm{Q}_{\mathrm{F}} / \mathrm{Q}_{\mathrm{H}}$ ratio.

\begin{tabular}{cc}
\hline Statistical Parameters & Value Parameters \\
\hline Sample size & 19 \\
\hline The arithmetic mean & 1.87 \\
\hline Moda & 1.49 \\
\hline Standard deviation & 1.10 \\
\hline Extremums & $1.07-5.31$ \\
\hline
\end{tabular}

The lower extremum and the values close to it correspond, as a rule, to sands and sandy loam; at a higher content of fine fractions, it corresponds to soils of plakor positions. The upper extremum is typical for the blocked loams, marsh soils in depressions, and soils under closed forests with sufficiently powerful heat-insulating covers on the surface. The difference between the modal value and the arithmetic mean shows that the distribution curve $Q_{F} / Q_{H}$ has a positive asymmetry, which indicates a weak knowledge of soils in the range of reduced values of the ratio $Q_{F} / Q_{H}$.

Statistical parameters are used to scale the stability estimates of geosystems. As a quantum of variability, the value of sigma-standard deviation is accepted, thus the scale is called sigmal. The number of classes is determined by the well-known Sturgess formula [15]. The result is a scale that includes four classes of state (Table 3).

Table 3. Scale of thermal energy resistance of permafrost geosystems to external influences.

\begin{tabular}{ccc}
\hline Stability Categories & Quanta of Variability & $\mathbf{Q}_{\mathbf{F}} / \mathbf{Q}_{\mathbf{H}}$ \\
\hline I. Stable & $\mathrm{M}+1,5 \sigma$ & $>3.5$ \\
\hline II. Resilient & $\mathrm{M}+1,0 \sigma$ & $3.0-3.4$ \\
\hline III. Plastically stable & $\mathrm{M}-1,0 \sigma$ & $0.8-2.9$ \\
\hline IV. Unstable & $\mathrm{M}-1,5 \sigma$ & $<0.7$ \\
\hline
\end{tabular}

Qualitative characteristics of the scale are as follows:

- I class-stable. Soils have high thermal inertia due to low (below -4 to $-5{ }^{\circ} \mathrm{C}$ ) average annual temperatures in the soles of the seasonal layer and the significant development of heat cycles, causing an increase in the "cold reserve" in the soil. The heat cycle of $Q_{F}$ by modulo exceeds $50 \mathrm{MJ} / \mathrm{m}^{2}$ and technogenic effects quickly recovered without recurrence of environmental effects.

- II class-resilient. The thermal inertia of the soil is high. The average annual temperature in the sole of the active layer is about -3 to $+4{ }^{\circ} \mathrm{C}$. The heat cycle of the cold period in absolute value ranges from $30-45 \mathrm{MJ} / \mathrm{m}^{2}$. Anthropogenic-destructive processes the damped natural recovery of the bioconversion of soil and ground vegetation layers. There is full recovery without saving traces.

- Class III-plastically stable. The thermal-inertial capacity of soils is reduced because the permafrost is high -1.5 to $-2.5{ }^{\circ} \mathrm{C}$, thus in the subsoil accumulates a relatively small "cold reserve", and the heat cycle $Q_{F}$ reaches only $20-30 \mathrm{MJ} / \mathrm{m}^{2}$. Destructive processes fade with the preservation of residual phenomena in the form of thermokarst funnels, thermoerosion furrows, etc.

- Class IV-unstable. Thermal inertia of soils is insignificant. The temperature on the sole of the active layer is -0.7 to $-1.5{ }^{\circ} \mathrm{C}$ and above. Heat cycle $Q_{\mathrm{F}}$ is in the range of $13-15 \mathrm{MJ} / \mathrm{m}^{2}$. The destructive processes occur in self-sustaining mode. The soil cover is completely destroyed, and the material is subjected to redeposition and formed bijarani.

Testing of the proposed scale shows that sustainable soils are characterized by indigenous and imaginary permafrost-taiga geosystems. Thus, the greatest difference in $\mathrm{Q}_{\mathrm{F}}-\mathrm{Q}_{\mathrm{H}}$, reaching $25-40 \mathrm{MJ} / \mathrm{m}^{2}$, 
is observed in Cryosols. It is in these soils that the gap between the depth of potential freezing and actual thawing is greatest, which implies high soil stability in the natural state and the need for intense energy impact to disrupt the established thermal equilibrium. As resilient assessed swamp geosystems, the drained options were plastically stable. In the permafrost meadow-chernozem steppes, the thermal energy difference does not exceed $10 \mathrm{MJ} / \mathrm{m}^{2}$, i.e., the natural margin of safety of the permafrost environment is small here. It is interesting to note that in similar geosystems of Central Yakutia, the difference in $\mathrm{Q}_{\mathrm{F}}-\mathrm{Q}_{\mathrm{H}}$ reaches $16 \mathrm{MJ} / \mathrm{m}^{2}$. This is evidence of both the increasing severity of the soil climate and the increased energy resistance of soils to changes in surface conditions. These geosystems are too resilient. Tracts of high bottom-lands are plastically stable, but under cultivation options, tracts of low floodplains have a lower resistance.

When cutting forests, the first target of conversion changes is forest litter. According to our data, the maximum temperature jump in the moss-peat layer under the indigenous high-closed larch forest is observed in May and is $14^{\circ} \mathrm{C}$ in the natural bedding [16]. By autumn, the temperature on the surface of the cover and below it is leveled. In the winter, there is an inversion of the sign of the temperature jump, i.e., there is a natural seasonal change of the cooling effect to the warming one. At the latitudes of Transbaikalia, the general thermophysical effect of organogenic ground covers is cooling. This is evidenced by the calculations of their thermal resistance, which in the thawed state $\left(R_{H}\right)$ is equal to $0.12-0.30$ and in the frozen $\left(R_{F}\right)$ state is only $0.03-0.05\left(\mathrm{~m}^{2} \mathrm{~K}\right) / \mathrm{W}$, i.e., the ratio of $R_{F} / R_{H}<1$, which is also true for other permafrost regions. However, in high latitudes, the overall effect of organogenic covers becomes warming [14].

When the forest is reduced and there is destruction of the organogenic cover, the soil experiences heat stroke. According to A. Pavlov [8,12], heat flows under the forest are one third to two thirds of the heat flow in the soils of the open area. The amplitude of the daily fluctuations of the heat flow to the ground at the cutting by $66.4 \mathrm{~W} / \mathrm{m}^{2}$ more than under the forest, and the heat content in the layer $0-0.2 \mathrm{~m}$ of bare soil in May is $1.74 \mathrm{MJ} / \mathrm{m}^{2}$. In the summer months, the difference in the heat content of the soil in the felling and under the forest is kept within $1.2 \mathrm{MJ} / \mathrm{m}^{2}$, and by the end of September, it falls to zero (Figure 1).

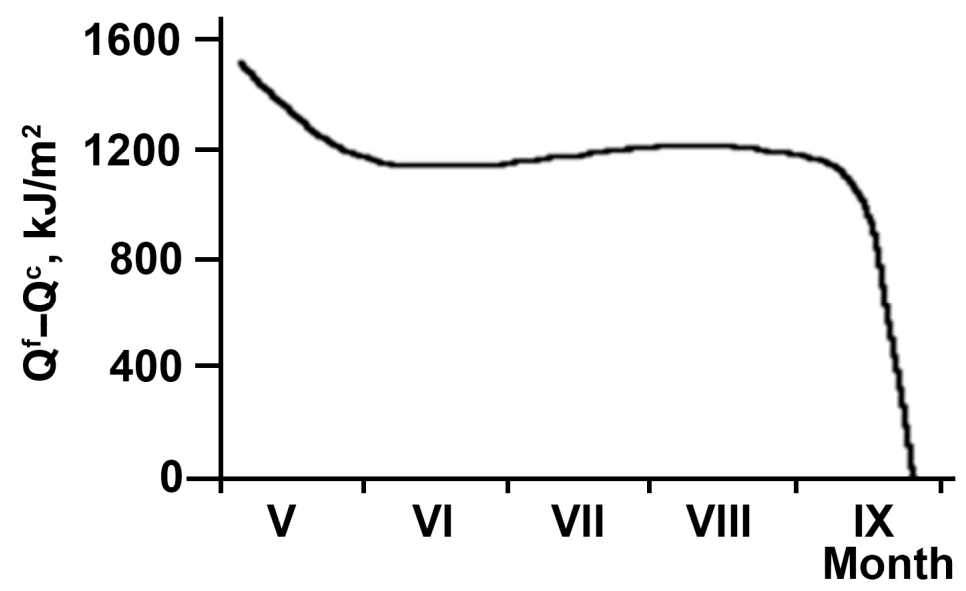

Figure 1. The difference between the heat content of soils in the felling $\left(\mathrm{Q}^{\mathrm{C}}\right)$ and under the forest $\left(\mathrm{Q}^{\mathrm{F}}\right)$.

Changes of conditions are accompanied by an increase in the depth of heat cycles. Thus, the daily temperature wave in the bare soil penetrates to a depth of $0.5-0.6 \mathrm{~m}$, which is $0.1-0.2 \mathrm{~m}$ more than in the soil under the forest. Also, the power of the layer of annual heat cycles changes, as evidenced by the increase in the average depth of soil thawing by $0.3-0.7 \mathrm{~m}$ in the cutting areas. It is interesting to note the fact that the reduction of forests and changes in soil climate are extended by about 10-15 days of soil stay in the thawed state, therefore slightly improving conditions for excavation. 
Based on the Fourier law [17], it is possible to determine the change in penetration depth and multi-year temperature fluctuations at the change of external conditions of heat exchange by the known formula:

$$
h=\sqrt{12 a \tau},
$$

where $\alpha$ is thermal diffusivity $\left(\sim 0.005 \mathrm{~m}^{2} / \mathrm{h}\right)$, and $\tau$ is time elapsed after changes.

It was found that in 10, 20, and 50 years after deforestation and destruction of ground cover, temperature changes penetrate to a depth of 70,100 , and $160 \mathrm{~m}$, respectively.

\section{Conclusions}

The lack of instrumental information for assessing the stability of soils to external changes at this stage can be offset by the calculated information. It was found that permafrost soils are characterized by increased annual heat cycle, the value of which usually exceeds $300 \mathrm{MJ} / \mathrm{m}^{2}$. This is due to the high heat consumption for the phase transformation of moisture, a portion of which always exceeds half of the annual heat cycle. It was shown that the ratio of elementary heat flows in frozen $\left(\mathrm{Q}_{\mathrm{F}}\right)$ and thawed $\left(\mathrm{Q}_{\mathrm{H}}\right)$ soil in permafrost regions always meets the condition $\mathrm{Q}_{\mathrm{F}}>\mathrm{Q}_{\mathrm{H}}$, i.e., the heat cycle of a cold period more than a warm period. This condition is the basis of the fundamental indicator of the cryolithozone-negative average annual soil temperature and the difference in $\mathrm{Q}_{\mathrm{F}}-\mathrm{Q}_{\mathrm{H}}$-energy assessments of excess layers of potential seasonal freezing over the layer of actual thawing. For the evaluation of soil resistance, we developed the statistical scale of $\mathrm{Q}_{\mathrm{F}} / \mathrm{Q}_{\mathrm{H}}$.

Author Contributions: Conceptualization, A.K.; Investigation, A.K., N.B., D.S. and A.G.; Methodology, A.K.; Writing-review \& editing, A.K., N.B., D.S. and A.G.

Funding: The study was funded by the budget projects AAAA-A17-117011810038-7, AAAA-A17-117112870130-4.

Conflicts of Interest: The authors declare no conflict of interest.

\section{References}

1. Kupriyanova, T. Overview of the concepts of the stability of physic geography systems. In The Stability of Geosystems; Science: Moscow, Russia, 1983; pp. 7-13. (In Russian)

2. Grodzinsky, M. Quantitative indicators of the stability of geosystems to meliorative effects and methods for their assessment. Phys. Geogr. Geomorphol. 1987, 34, 10-17. (In Russian)

3. Shkopek, V.; Vakhal, Ya.; Orts, R. Theoretical background and content of the method of landscape stabilization. Izvestiya Vsesoyuznogo Geogr. Obshestva 1989, 121, 382-387. (In Russian)

4. Garagulya, L.; Gordeeva, G. The ecological role of permafrost rocks. Geoecology 2002, 5, 403-410. (In Russian)

5. Schuster, P.F.; Schaefer, K.M.; Aiken, G.R.; Antweler, R.C.; Dewild, J.F.; Gryziec, J.D.; Gusmeroli, A.; Hugelius, G.; Jafarov, E.; Krabbenhoft, D.P.; et al. Permafrost Stores a Globally Significant Amount of Mercury. Geophys. Res. Lett. 2018, 45, 1463-1471. [CrossRef]

6. Parmuzin, S.; Sukhodolsky, S. The experience of zoning of a territory with strong icy rocks on stability to man-made impacts (for example of the Middle Yamal). In Surface Stability to Man-Made Impacts in the Eternal Permafrost Region; Publishing house of the Institute of Permafrost, USSR, Academy of Sciences: Yakutsk, Russia, 1980; pp. 108-127. (In Russian)

7. Kulikov, A.; Dugarov, V.; Korsunov, V. Permafrost Soils: Ecology, Power System and Productivity Forecast; Buryat Science Center SB RAS: Ulan-Ude, Russia, 1997; p. 312. (In Russian)

8. Pavlov, A. Energy Exchange in the Landscape Sphere of the Earth; Science: Novosibirsk, Russia, $1984 ;$ p. 256. (In Russian)

9. Savvinov, D. The role of perennial permafrost in the formation of the hydrothermal regime of soils. In Soils of the Baikal-Amur Mainline; Science: Novosibirsk, Russia, 1979; pp. 282-287. (In Russian)

10. Balobaev, V. Geothermy of the Frozen Zone of the Lithosphere of the North of Asia; Science: Novosibirsk, Russia, 1991; p. 193. (In Russian)

11. Gavrilova, M. Modern Climate and Eternal Permafrost on the Continents; Science: Novosibirsk, Russia, 1981; p. 113. (In Russian)

12. Pavlov, A. Cryolithozone Monitoring; Geo: Novosibirsk, Russia, 2008; p. 229. (In Russian) 
13. Fundamentals of Geocryology (Permafrost); Academy of science USSR: Moscow, Russia, 1959; Volume 1, p. 459. (In Russian)

14. General Permafrost Studies; Moscow State University: Moscow, Russia, 1978; p. 463. (In Russian)

15. Sturges, H. The Choice of a class-interval. J. Am. Stat. Assoc. 1926, 21, 65-66. [CrossRef]

16. Kulikov, A.; Tsibikdorzhiev, T. Thermal role of ground cover in Transbaikalia. Geogr. Nat. Resour. 1994, 2, 100-106. (In Russian)

17. Fourier, J. Analytical Theory of Heat; Dover Publications: New York, NY, USA, 1955.

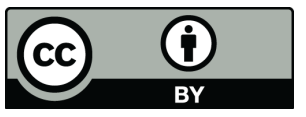

